\title{
A novel experimental porcine model to assess the impact of differential pulmonary blood flow on ischemia-reperfusion injury after unilateral lung transplantation
}

Anna Elisabeth Frick ${ }^{*}$ (D), Michaela Orlitová ${ }^{2}$ Arno Vanstapel ${ }^{2}$, Sofie Ordies ${ }^{1}$, Sandra Claes $^{3}$, Dominique Schols ${ }^{3}$, Tobias Heigl ${ }^{2}$, Janne Kaes², Berta Saez-Gimenez ${ }^{2,4}$, Robin Vos ${ }^{2,5}$, Geert M. Verleden ${ }^{2,5}$, Bart Vanaudenaerde², Stijn E. Verleden ${ }^{2}$, Dirk E. Van Raemdonck ${ }^{2,6}$ and Arne P. Neyrinck ${ }^{1,7}$

*Correspondence: annaelisabeth.frick@ymail. com

${ }^{1}$ Department of Cardiovascular Sciences, KU Leuven, Leuven, Belgium Full list of author information is available at the end of the article

\begin{abstract}
Background: Primary graft dysfunction (PGD) remains a major obstacle after lung transplantation. Ischemia-reperfusion injury is a known contributor to the development of PGD following lung transplantation. We developed a novel approach to assess the impact of increased pulmonary blood flow in a large porcine single-left lung transplantation model.
\end{abstract}

Materials: Twelve porcine left lung transplants were divided in two groups $(n=6$, in low- (LF) and high-flow (HF) group). Donor lungs were stored for $24 \mathrm{~h}$ on ice, followed by left lung transplantation. In the HF group, recipient animals were observed for $6 \mathrm{~h}$ after reperfusion with partially clamping right pulmonary artery to achieve a higher flow (target flow 40-60\% of total cardiac output) to the transplanted lung compared to the LF group, where the right pulmonary artery was not clamped.

Results: Survival at $6 \mathrm{~h}$ was 100\% in both groups. Histological, functional and biological assessment did not significantly differ between both groups during the first $6 \mathrm{~h}$ of reperfusion. injury was also present in the right native lung and showed signs compatible with the pathophysiological hallmarks of ischemia-reperfusion injury.

Conclusions: Partial clamping native pulmonary artery in large animal lung transplantation setting to study the impact of low versus high pulmonary flow on the development of ischemia reperfusion is feasible. In our study, differential blood flow had no effect on IRI. However, our findings might impact future studies with extracorporeal devices and represent a specific intra-operative problem during bilateral sequential single-lung transplantation.

Keywords: Porcine left lung transplantation, Primary graft dysfunction, Pulmonary vascular resistance (c) The Author(s) 2021. Open Access This article is licensed under a Creative Commons Attribution 4.0 International License, which permits use, sharing, adaptation, distribution and reproduction in any medium or format, as long as you give appropriate credit to the original author(s) and the source, provide a link to the Creative Commons licence, and indicate if changes were made. The images or other third party material in this article are included in the article's Creative Commons licence, unless indicated otherwise in a credit line to the material. If material is not included in the article's Creative Commons licence and your intended use is not permitted by statutory regulation or exceeds the permitted use, you will need to obtain permission directly from the copyright holder. To view a copy of this licence, visit http:// creativecommons.org/licenses/by/4.0/. 


\section{Introduction}

Primary graft dysfunction (PGD) occurs within the first $72 \mathrm{~h}$ after lung transplantation (LTx) and it is clinically reflected by impaired gas exchange, alveolar infiltrates on chest X-ray, and pulmonary edema representing acute allograft ischemia-reperfusion injury (IRI) [1]. PGD is associated with early morbidity and mortality [2]. PGD has a multifactorial nature with well-studied donor, procedural, and recipient risk factors. The major component responsible for PGD is still ischemia-reperfusion injury (IRI) [3].

The hallmark of IRI is the increased permeability of the alveolo-capillary membrane. Once reperfusion of the transplanted allograft occurs, ROS and pro-inflammatory cytokines activate neutrophils and upregulation of cell-surface adhesion molecules on the endothelial side of the lung occurs. The following disruption of alveolo-capillary membrane results in increased microvascular permeability, increased PVR, impaired oxygenation and eventually pulmonary edema $[4,5]$. Endothelial cells are exposed to tangential shear stress and circumferential wall stretch by the blood flow through the pulmonary vasculature [6].

Alterations in endothelial shear stress (such as the interruption and re-installation of flow during IRI) result in a cellular signaling cascade which can contribute to trigger inflammation in the process of IRI itself [7].

Animal models provide a broad study field to verify clinical findings and are the cornerstone of translational research. The single-left porcine LTx model is commonly used to study the early stages of lung transplantation, and especially IRI. The current described single-lung transplant models have some shortcomings. Most models do not clamp the contralateral native lung after the allograft is reperfused. In this way, it is not possible to control the flow, which is an important driver of IRI based on shear stress alterations, over the newly transplanted lung [12-14].

Studies with (partial) clamping of the right PA would therefore help to improve our understanding of IRI. In addition, this might also be important to understand the intraoperative consequences of sequential bilateral lung transplant procedures. During these procedures, the first implanted lung receives the complete cardiac output when the second graft is transplanted. To avoid this overflow to the new lung and to control the pulmonary flow and RV function, installation of extracorporeal techniques is often considered. In this study using healthy pig donor lungs with identical ischemic intervals and lung preservation methods, we wanted to dissect out the impact of pulmonary flow itself during early reperfusion of the allograft in the development of ischemia-reperfusion injury, both to optimize current transplant models and to study the intra-operative clinical issues regarding bilateral sequential lung transplantation without extracorporeal life support (ECLS).

A left-single lung transplantation survival model with clamping of the right pulmonary artery was chosen because sequential bilateral lung transplantation in pigs is not possible because of anatomic differences with the presence of a separate tracheal bronchus to the right upper lobe and an accessory right lower lobe draining into the left inferior pulmonary vein.

We hypothesized that IRI in the allograft is more severe in a high-flow than in a lowflow reperfusion model. 


\section{Materials and methods}

This experimental porcine study (topig20 pigs, Zoötechnisch centrum KU Leuven, Lovenjoel, Belgium) was approved by the Ethics Committee on Animal Research KU Leuven (P011/2018). All animals received human care in accordance with "Principles of Laboratory Animal care", formulated by the National Society for Medical Research and "Guide for the Care and Use of Laboratory Animals", prepared by the Institute of Laboratory Animal Resources and published by the National Institutes of Health, USA (NIH Publication No. 86-23, revised 1996).

\section{Study groups}

24 domestic male pigs (Topigs 20) were divided into two groups: high-flow (HF) $(n=6 \times$ donor + recipient $)$ and low-flow (LF) $(n=6 \times$ donor + recipient $)$ group. The mean body weight of the recipient animals was $52.7( \pm 0.90) \mathrm{kg}$ in the LF and 52.3 $( \pm 2.07) \mathrm{kg}$ in the HG group. The donor animals had a mean body weight of 50.47 $( \pm 1.19) \mathrm{kg}$ in the LF and $49.5( \pm 1.39) \mathrm{kg}$ in the HF group. There was no significant difference in body weight between the groups.

In both groups, lungs were harvested after cold antegrade flush in the donor animal. After 24-h cold ischemia by storage on $4{ }^{\circ} \mathrm{C}$ ice, the left graft was transplanted in a recipient animal. 24-h cold storage is a very long period for lung preservation that is not clinically relevant. However, in order to induce sufficient graft injury resulting in IRI, we opted for a model of 24-h cold ischemia reported as a standard model in many other publications investigating IRI.

In the HF group, the right native pulmonary artery was left unclamped for $2 \mathrm{~h}$ after reperfusion to avoid imminent right heart failure. Thereafter, the PA was partially clamped for the remaining $4 \mathrm{~h}$ to achieve a flow to the transplanted left allograft (target flow $40-60 \%$ of total cardiac output). In the LF group, the right PA was not clamped. Hemodynamic parameters and gas exchange were measured during $6 \mathrm{~h}$ of reperfusion in both groups.

\section{Donor procedure}

After sedating the donor animal with an intramuscular injection of $5 \mathrm{mg} / \mathrm{kg}$ Zoletil 100 (Virbac, Carros, France) and $3 \mathrm{mg} / \mathrm{kg}$ Xyl-M 2\% (VMD, Arendonk, Belgium), anesthesia was maintained with $10 \mathrm{mg} / \mathrm{kg} / \mathrm{h}$ propofol, $20 \mu \mathrm{g} / \mathrm{kg} / \mathrm{h}$ fentanyl and intermittent boli of pancuronium $2 \mathrm{mg}$ for muscle relaxation. Animals were intubated with a 7.0-mm endotracheal tube and ventilated (Aestiva 3000; GE Healthcare Europe GmbH, Little Chalfont, UK) with a tidal volume (TV) of $8 \mathrm{ml} / \mathrm{kg}$, positive end-expiratory pressure (PEEP) of $5 \mathrm{cmH}_{2} \mathrm{O}$ and $\mathrm{FiO}_{2}$ of $30 \%$. Respiratory rate (RR) was adjusted to endtidal carbon dioxide levels $\left(\mathrm{ETCO}_{2}\right)(45-55 \mathrm{mmHg})$. A lateral right neck incision was made to access the right carotid artery for invasive monitoring of arterial blood pressure (ABP). Median sternotomy was performed. Prior to cardiac arrest induced by aortic cross-clamping, all animals were anticoagulated with $300 \mathrm{IU} / \mathrm{kg}$ heparin. The thymus was resected and the pericardium opened. Inferior (IVC) and superior (SVC) caval veins were isolated, and the aorta was separated before PA cannulation. After ligation of SVC and IVC and aortic cross-clamp, grafts were flushed antegrade via the PA cannula with $2 \mathrm{~L}(\mathrm{~L})$ of cold $\left(4^{\circ} \mathrm{C}\right)$ buffered $\mathrm{OCS}^{\circledR}$ solution (Transmedics, Andover, MA, USA). 
Heart-lung block was harvested and the trachea was double-clamped with lungs being inflated and maintaining an airway pressure of $15 \mathrm{cmH}_{2} \mathrm{O}$. On the back table a retrograde cold flush with $800 \mathrm{~mL}$ buffered OCS solution was performed via the pulmonary veins following excision of the heart. Lungs were placed in two plastic bags and stored in $\mathrm{OCS}^{\circledR}$ solution at $4{ }^{\circ} \mathrm{C}$ for $24 \mathrm{~h}$.

\section{Recipient procedure}

After anesthetizing the recipient animal and maintaining anesthesia as described above for the donor procedure, a central venous catheter was inserted in the internal jugular vein as well as an arterial catheter in the carotid artery. A mini-laparotomy was performed to insert a bladder catheter. Animal body temperature was monitored with a rectal probe. The pig was turned to a right lateral decubitus position and a left thoracotomy in the 4th intercostal space was performed. All animals were heparinized with $300 \mathrm{IU} / \mathrm{kg}$. After dissection of the pulmonary ligament and ligation of the left hemi-azygos vein, a left pneumonectomy was performed. PA pressure (PAP) and left atrium (LA) pressure (LAP) were monitored with catheters inserted in the common PA and LA by direct surgical cannulation. PA blood flow was measured by transonic flowprobes (Transonic Systems Inc. ${ }^{\circledR}$, Ithaca, NY) based on patented ultrasound transit-time technology. The left donor lung was transplanted by three anastomoses in the following order: (1) bronchus with a running 4-0 PDS suture on the posterior and anterior walls; (2) LA cuff with a running 5-0 prolene suture; and (3) PA with a running 5-0 prolene suture as previously described. [11] After opening clamps, the graft was reperfused and the animal was monitored for $6 \mathrm{~h}$. Whenever necessary, norepinephrine (Levophed, Pfizer Inc., US) was administrated intravenously for vasopressor support to maintain mean ABP above $50 \mathrm{mmHg}$ starting with an initial dose of $8-12 \mathrm{mcg} / \mathrm{min}$ continuously. Lactate ringer was added $(8 \mathrm{ml} / \mathrm{kg} / \mathrm{h})$ to maintain fluid balance. During implantation of the left lung, tidal volume (TV) was corrected due to right-single lung ventilation. To reflect this in our model, lungs were ventilated with a TV of $8 \mathrm{ml} / \mathrm{kg}$ and PEEP of $5 \mathrm{cmH}_{2} \mathrm{O}$ during the baseline procedure and TV was reduced to $2 / 3$ after pneumonectomy and during implantation. TV was then switched back to $8 \mathrm{ml} / \mathrm{kg}$ upon reperfusion. At the end of the experiment, animals were killed while on deep anesthesia by aortic clamping.

\section{Sampling}

Upon reperfusion and during the monitoring period, blood samples were taken hourly from the carotid artery, PA via the indwelling catheter, and right and left pulmonary veins (RPV, LPV) by repeated direct puncture to monitor gas exchange.

Differential blood gases from RPV and LPV allowed to discriminate the oxygenation capacity of the right native versus the left transplanted lung. In between sampling, the left chest cavity was closed temporarily and reopened hourly for sampling blood gases directly from the left and right pulmonary vein to measure differential oxygenation by both lungs while ventilated with $\mathrm{FiO} 21.0$ and PEEP $5 \mathrm{~cm} \mathrm{H}_{2} \mathrm{O}$. At the end of the experiment, a broncho-alveolar lavage (BAL) with two times $20 \mathrm{cc}$ saline $0.9 \%$ was performed in the left lower lobe and the supernatant was analyzed with a porcine multiplex enzyme-linked immuno-sandwich assays (ELISA) kit for measurement of interleukin-6 (IL-6) and interleukin-8 (IL-8) levels according to the manufacturer's 
protocol (R\&D Systems, Inc. Minneapolis, MN, USA) with lower limits of quantification (LLOQ): $4.69 \mathrm{pg} / \mathrm{ml}$ for IL-6 and $31.25 \mathrm{pg} / \mathrm{mg}$ for IL-8 (Fig. 1).

Porcine multiplex ELISA according to the manufacturer's protocol (ThermoFisher, Scientific, Vienna, Austria) were performed on plasma samples, collected from each animal at baseline and at the end of the experiment for cytokine analysis, including interferon- $\alpha$ (IFN- $\alpha)$, interferon- $\gamma$ (IFN- $\gamma)$, interleukin-1beta (IL-1 $\beta)$, interleukin-10 (IL-10), interleukin-12p40 (IL-12p40), interleukin-4 (IL-4), interleukin-6 (IL-6), interleukin-8 (IL-8), and tumor necrosis factor- $\alpha$ (TNF- $\alpha$ ) with lower limits of quantification (LLOQ): $0.6 \mathrm{pg} / \mathrm{ml}$ for IFN- $\alpha, 4.5 \mathrm{pg} / \mathrm{ml}$ for IFN- $\gamma, 3.2 \mathrm{pg} / \mathrm{ml}$ for IL- $1 \beta, 18 \mathrm{pg} / \mathrm{ml}$ for IL-10, $30 \mathrm{pg} / \mathrm{ml}$ for IL-12p40, $1.5 \mathrm{pg} / \mathrm{ml}$ for IL-4, $5.9 \mathrm{pg} / \mathrm{ml}$ for IL-6, $16 \mathrm{pg} / \mathrm{ml}$ for IL-8, $6.5 \mathrm{pg} / \mathrm{ml}$ for TNF- $\alpha$.

Lung biopsies were taken from the right and left lower lobe (RLL, LLL) from the recipient at the end of the experiment and from RLL of the (unused) donor lung at the end of the experiment and subsequently formalin fixed, paraffin embedded, and hematoxylin-eosin stained. Biopsies were scored for presence of interstitial widening, capillary congestion, intra-alveolar edema, hemorrhage, neutrophils in septa and in alveoli, and eosinophils in septa by a pathologist blinded for experimental groups. Also, biopsies for wet-to-dry weight (W/D) ratio calculation (after $72 \mathrm{~h}$ in the oven at $80^{\circ} \mathrm{C}$ ) were taken from the right and left lower lobe (RLL, LLL) to quantify lung edema [15].

\section{Statistical analysis}

All data are described as median with interquartile range (IQR) (25\% QI-75\% QI) in GraphPad Prism 8 (GraphPad Software Inc, La Jolla, CA, USA). Values were compared between time points (T0-T6) and between both study groups using 2-way ANOVA for repeated measures or Mann-Whitney U-test and post hoc multiple comparison test Sidak (x). $p$-values of $\leq 0.05$ was considered significant.

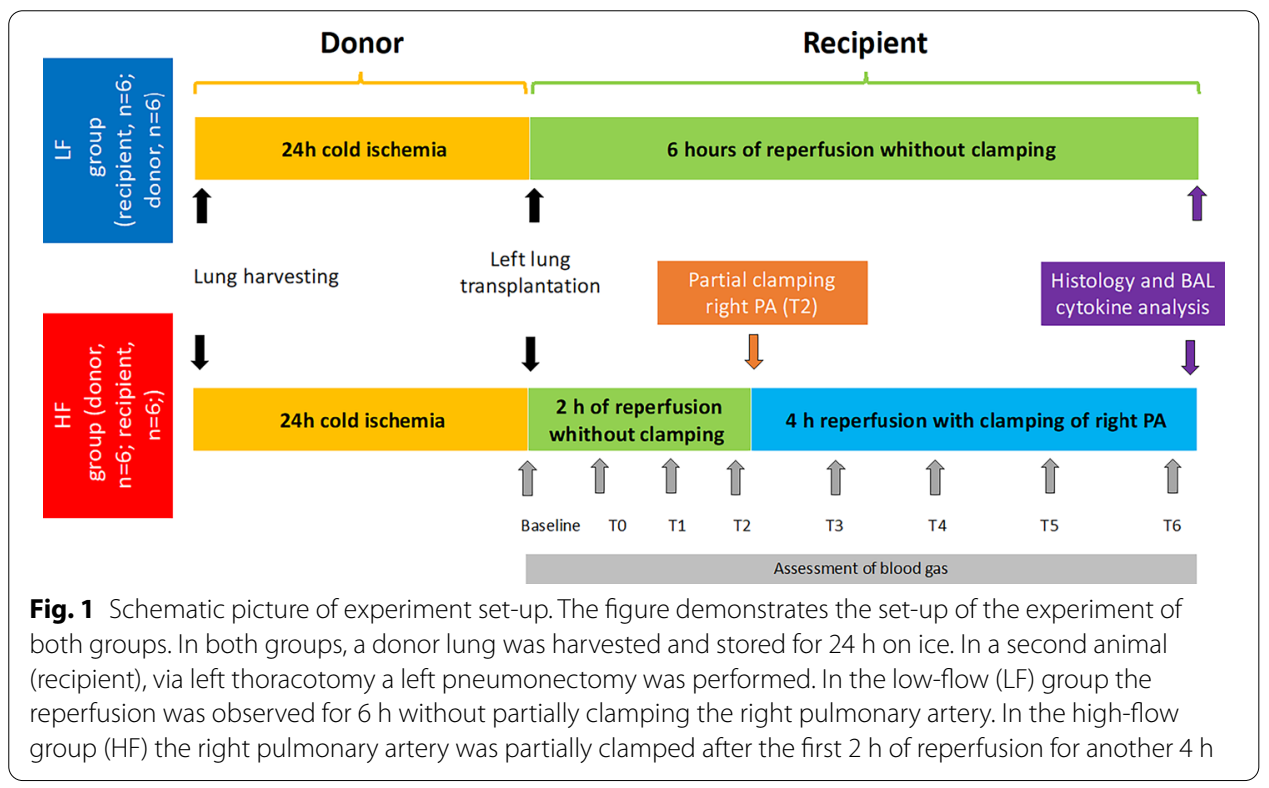




\section{Results}

\section{Functional assessment during $6 \mathrm{~h}$ of reperfusion}

Table 1 demonstrates parameters assessed at the time of baseline (before performing the left thoracotomy and left pneumonectomy in the recipient animal), at the time of reperfusion (T0), after 1 (T1), 2 (T2), 3 (T3), 4 (T4), 5 (T5) and 6 (T6) hours of reperfusion (Table 1).

Physiological parameters assessed over the 6-h reperfusion period and are presented in Fig. 2.

Cardiac output was comparable over time between both groups ( $p=0.32$ ) (Fig. 2a).

As intended by the experimental design, minute blood flow to the left allograft over the $6 \mathrm{~h}$ was higher in HF (1.41 L) compared to LF $(0.49 \mathrm{~L}) ; p=0.0005$ (Fig. 2b). Other way around, blood flow to the right native lung was significantly lower in HF $(2.77 \mathrm{~L}$ vs $3.40 \mathrm{~L} ; p=0.04)$. Post hoc analysis demonstrated significant differences in flow to the allograft at 5 and $6 \mathrm{~h}(p=0.03$ and $p=0.0002$, respectively) and in the native lung at $6 \mathrm{~h}(p=0.04)$ of reperfusion (Fig. 2c).

$\mathrm{P} / \mathrm{F}$ ratios of LPV and RPV were not significant $(p=0.08$ and $p=0.60)$ (Fig. $2 \mathrm{~d}-\mathrm{f}$ ).

Mean PAP was not different in the HF group vs. the LF group $(34.6 \mathrm{mmHg}$ vs. $29.8 \mathrm{mmHg})(p=0.16)$ (Fig. $2 \mathrm{~g})$. After $6 \mathrm{~h}$ reperfusion $\mathrm{W} / \mathrm{D}$ of right native lung $(p=0.49)$ and left transplanted lung were similar $(p>0.99)$ (Fig. 3a).

\section{Immunological evaluation}

Porcine multiplex ELISA analysis of the plasma at the end of the experiment between LF and HF group for the cytokines IFN- $\alpha$, IFN- $\gamma$, IL-1 $\beta$, IL-10, IL-12p40, IL-4, IL-6, IL- 8 and TNF- $\alpha(p=0.32)$ did not show any differences between both groups (Table 2). Similarly, no significant differences were demonstrated in the single cytokine ELISA analysis of BAL samples between the LF and HF group (IL-6, $p=0.23$, IL-8, $p=0.07$ ).

\section{Histology}

Histologic abnormalities in the left allograft and the right native lung were comparable between LF and HF groups (Fig. 3b-e).

Histological scoring of lung biopsies is shown in Table 3. In HF no differences were found between the right native lung and left allograft, though more neutrophils were observed in septa $(p=0.02)$ and neutrophils in the alveoli in the allograft compared to the native lung $(p=0.01)$.

\section{Discussion}

In this study, we have introduced a novel approach to study the impact of pulmonary flow as a contributor to develop ischemia-reperfusion injury after one-lung transplantation in a large animal model. The unique aspect of our model is multiple. First, we demonstrate the feasibility of selective manipulation of pulmonary flow to investigate ischemia-reperfusion injury. Secondly, our model represents a specific intraoperative phase during sequential bilateral lung transplantation where the pulmonary flow is forced through the newly transplanted first lung. Finally, our model offers the 
Table 1 Outcome parameters from baseline till the end of reperfusion (T6)

\begin{tabular}{|c|c|c|}
\hline Number of pigs, $n$ & $\begin{array}{l}\text { Low flow } \\
6\end{array}$ & $\begin{array}{l}\text { High flow } \\
6\end{array}$ \\
\hline \multicolumn{3}{|l|}{ Donor } \\
\hline Body weight, kg & $50.5( \pm 1.2)$ & $49.5( \pm 1.4)$ \\
\hline $\mathrm{pO} 2, \mathrm{mmHg}$ & $539.5(450-568.3)$ & $525(452.5-555)$ \\
\hline $\mathrm{pCO} 2$ & $41.7(38.3-42.9)$ & $42.5(41.7-43.4)$ \\
\hline \multicolumn{3}{|l|}{ Recipient } \\
\hline Body weight, kg & $52.7( \pm 0.9)$ & $52.3( \pm 2.1)$ \\
\hline \multicolumn{3}{|l|}{ Baseline } \\
\hline mPAP, $\mathrm{mmHg}$ & $24(18.8-29.5)$ & $22.5(19-28.5)$ \\
\hline $\mathrm{pCO} 2$ & $49.8(44.4-52.1)$ & $48.5(39.6-50.8)$ \\
\hline pO2 (LPV), mmHg & $369(287.8-531)$ & $346(308-417.5)$ \\
\hline pO2 (RPV), mmHg & 426.5 (395.5-453.5) & $380(321-407.5)$ \\
\hline $\mathrm{CO}, \mathrm{L} / \mathrm{min}$ & $3.85(3.6-4.1)$ & $4.7(3.9-5.9)$ \\
\hline Flow left PA, L/min & $1.3(0.9-1.8)$ & $1.4(0.9-1.9)$ \\
\hline \multicolumn{3}{|l|}{ Reperfusion T0 } \\
\hline $\mathrm{mPAP}, \mathrm{mmHg}$ & $29.5(19-36.3)$ & $28.5(22.8-30.3)$ \\
\hline pCO2 & $47.4(37.2-54.4)$ & $46.3(43.3-57.4)$ \\
\hline pO2 (LPV), mmHg & $300(87.1-448)$ & $315.5(89.68-389.8)$ \\
\hline pO2 (RPV), mmHg & $325.5(280.5-425.5)$ & 371.5 (305.9-433.5) \\
\hline $\mathrm{CO}, \mathrm{L} / \mathrm{min}$ & $3.8(3.3-5)$ & $4.5(3.8-6.4)$ \\
\hline Flow left PA, L/min & $0.18(0.10-0.36)$ & $0.17(0.4-0.60)$ \\
\hline \multicolumn{3}{|l|}{ Reperfusion T1 } \\
\hline $\mathrm{mPAP}, \mathrm{mmHg}$ & $27.5(20.3-30.8)$ & $27.5(16.8-34.5)$ \\
\hline pCO2 & $46.2(42.6-52.3)$ & $48.3(44.9-54.2)$ \\
\hline pO2 (LPV), mmHg & $38(319-441.8)$ & $414.5(256.5-452.5)$ \\
\hline pO2 (RPV), mmHg & $371(297.3-460)$ & $416(344.3-448.3)$ \\
\hline $\mathrm{CO}, \mathrm{L} / \mathrm{min}$ & $38(2.9-5.4)$ & $4(3.4-4.6)$ \\
\hline Flow left PA, L/min & $0.32(0.19-0.48)$ & $0.39(0.25-0.95)$ \\
\hline \multicolumn{3}{|l|}{ Reperfusion T2 } \\
\hline $\mathrm{mPAP}, \mathrm{mmHg}$ & $32.5(28-34.5)$ & $37(29.3-42.3)$ \\
\hline pCO2 & $43.6(39.4-55.3)$ & $47.9(42.9-50.9)$ \\
\hline pO2 (LPV), mmHg & $352(278.3-446.5)$ & $291(71.1-493)$ \\
\hline pO2 (RPV), mmHg & 404 (319.3-447.8) & $410(298.8-472.8)$ \\
\hline $\mathrm{CO}, \mathrm{L} / \mathrm{min}$ & $4.2(3.3-4.7)$ & $3.8(3.1-4.2)$ \\
\hline Flow left PA, L/min & $1.1(0.5-1.9)$ & $1.5(0.6-2.2)$ \\
\hline \multicolumn{3}{|l|}{ Reperfusion T3 } \\
\hline mPAP, mmHg & $28.5(25.8-41.5)$ & $38(28.5-42.3)$ \\
\hline $\mathrm{pCO} 2$ & $46.8(43.7-49.1)$ & $48.3(44.6-54.5)$ \\
\hline pO2 (LPV), mmHg & 275 (194.9-358) & $118.2(79.3-296.5)$ \\
\hline pO2 (RPV), mmHg & $434(392.5-477.5)$ & $413.5(316-451)$ \\
\hline $\mathrm{CO}, \mathrm{L} / \mathrm{min}$ & $3.7(2.8-4.2)$ & $4(3.9-4.5)$ \\
\hline Flow left PA, L/min & $0.53(0.43-0.66)$ & $1.8(1.1-2.2)$ \\
\hline \multicolumn{3}{|l|}{ Reperfusion T4 } \\
\hline mPAP, mmHg & $32(21.5-40.3)$ & $38.5(34.8-45.3)$ \\
\hline pCO2 & $46.2(44.5-55.9)$ & $48.3(46.1-51.4)$ \\
\hline pO2 (LPV), mmHg & $270(86.2-331)$ & $97(77.2-215.3)$ \\
\hline pO2 (RPV), mmHg & 397.5 (349.5-454.8) & $322.5(172.8-430.8)$ \\
\hline $\mathrm{CO}, \mathrm{L} / \mathrm{min}$ & $3.6(3.3-4.4)$ & $4.1(3.4-4.9)$ \\
\hline Flow left PA, L/min & $0.69(0.36-0.91)$ & $1.7(1.2-2.5)$ \\
\hline
\end{tabular}


Table 1 (continued)

\begin{tabular}{llc}
\hline Number of pigs, $\mathbf{n}$ & Low flow & $\begin{array}{l}\text { High flow } \\
\mathbf{6}\end{array}$ \\
\hline Reperfusion T5 & $\mathbf{6}$ \\
mPAP, mmHg & $27.5(23.5-32)$ & $42.5(29.5-46.3)$ \\
pCO2 & $42.4(37.3-46.3)$ & $47.8(43.6-53.6)$ \\
pO2 (LPV), mmHg & $300.5(193.8-355)$ & $185.5(70.3-234.3)$ \\
pO2 (RPV), mmHg & $389.5(351.8-445.8)$ & $435.5(369.8-486.5)$ \\
CO, L/min & $3.5(3-5.1)$ & $4.2(3.4-4.8)$ \\
Flow left PA, L/min & $0.43(0.36-0.59)$ & $2.2(1.1-2.5)$ \\
\hline
\end{tabular}

Data are expressed as median (25\%-75\% interquartile range); and Mann-Whitney was used for comparing the two groups $\mathrm{CO}$ cardiac output, $P A$ pulmonary artery, $p \mathrm{O}_{2}$ partial pressure of oxygen, $p \mathrm{CO}_{2}$ partial pressure of carbon dioxide, $L P V$ left pulmonary vein, $R P V$ right pulmonary vein, $m P A P$ mean pulmonary arterial pressure, $T 0$ start of reperfusion (baseline), $T 1$ after $1 \mathrm{~h}$ reperfusion, $T 2$ after $2 \mathrm{~h}$ reperfusion, $T 3$ after $3 \mathrm{~h}$ reperfusion, $T 4$ after $4 \mathrm{~h}$ reperfusion, $T 5$ after $5 \mathrm{~h}$ reperfusion, $T 6$ after $6 \mathrm{~h}$ reperfusion, W/D wet-to-dry weight ratio, RLL right lower lobe, LLL left lower lobe, LF low flow, HF high flow

possibility to further investigate extracorporeal circuits that deviate the flow from the right ventricle to control ischemia-reperfusion injury and to support right ventricular function.

Many researchers have developed models of one-lung transplantation in large animals $[8-11,16]$. These models transplant a single allograft lung into a recipient animal. In some of these models, the contralateral lung is left untouched and unmodified and is still being fully perfused and ventilated. Others have excluded the non-transplanted lung completely from the circulation by clamping the hilum.

Therefore, these models have some major limitations in studying the ischemia-reperfusion injury.

First, when pulmonary flow is completely forced through the newly transplanted lung by excluding the native contralateral lung in the recipient animal, the perfusion injury might be irreversible since the pulmonary flow is too large. In addition, many of these models describe the need for circulatory support (type ECMO) to overcome hemodynamic instability caused by right ventricular failure (due to increased afterload).

Second, in the event, where the native contralateral lung is not clamped and fully integrated in the perfusion, it is difficult to control the flow through the newly transplanted lung. It might occur that due to high PVR, there is almost no flow passing through the vasculature of the transplanted lung. In this way, the model will not reflect a translational situation to study ischemia-reperfusion and ischemia might even be ongoing.

In order to overcome these problems, we have introduced a very innovative approach to better control the reperfusion of a newly transplanted lung in a large animal model by partially clamping the flow to the native lung and directly measuring the flow towards both lungs.

To avoid acute right ventricular failure, the right PA was only partially clamped as the non-dilatable suture line of the PA anastomosis of the left transplanted lung may create a relative obstruction and therefore cause an increased right ventricular afterload. Our technique to perform a wider PA anastomosis in our porcine LTx model was previously described [11].

All animals survived the 6-h reperfusion time and the partial PA clamping did not result in right ventricular failure right heart failure [17]. 

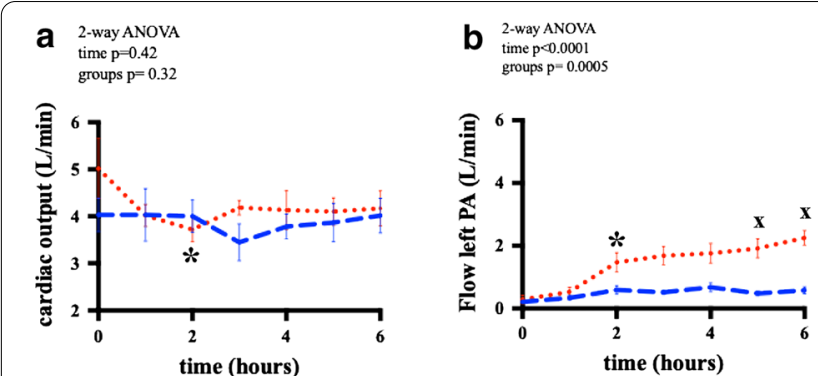

C $\begin{aligned} & \text { 2-way ANOVA } \\ & \text { time } \mathrm{p}-0.003\end{aligned}$ time $\mathrm{p}=0.003$
groups $\mathrm{p}=0.04$

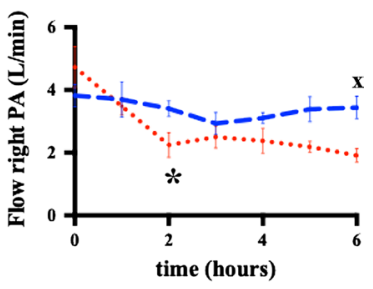

time (hours)

high flow low flow
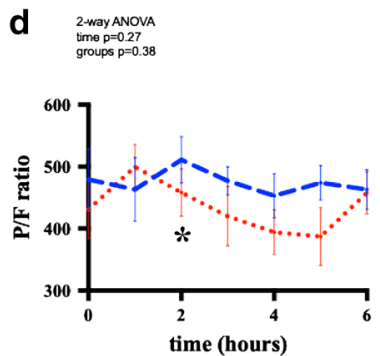

e 2-way ANOVA time $\mathrm{p}=0.01$
groups $\mathrm{p}=\mathbf{0 . 0 8}$

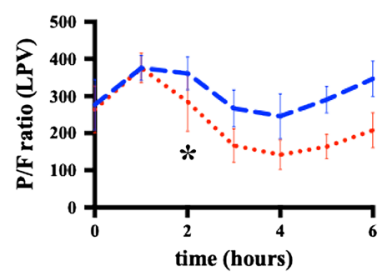

f 2-way ANOVA time $\mathrm{p}=0.30$
groups $\mathrm{p}=0.60$

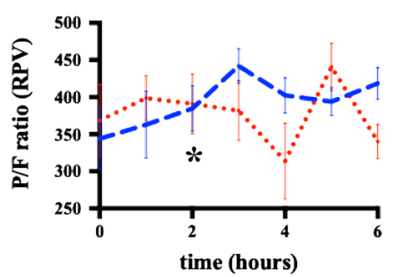

time (hours)

high flow - - low flow

9 2-way ANOVA time $\mathrm{p}=0.01$
groups $\mathrm{p}=0.16$

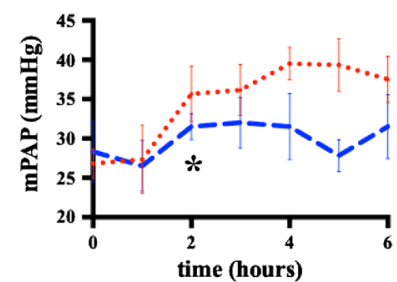

.. high flow

Fig. 2 Parameters during reperfusion. a-c Assessment of hemodynamic parameters during 6-h reperfusion. $\mathrm{CO}$ and flow to the left and right lung were measured, flow through the right PA was calculated. All data are depicted as median \pm IQR analyzed with repeated measures two-way ANOVA (a-c) and post hoc multiple comparison test Sidak (x). Time is 6-h reperfusion; CO, cardiac output; PA pulmonary artery; after $2 \mathrm{~h}$ of reperfusion, the right pulmonary artery was clamped in the high-flow group (*). d-f Assessment of oxygenation; blood gases samples were taken from carotid artery (P/F ratio), left pulmonary vein (LPV) and right pulmonary vein (RPV). All data are depicted as median $\pm I Q R$ analyzed with repeated measures two-way ANOVA (d-f) and post hoc multiple comparison test Sidak (x). Time is 6-h reperfusion; pO2, partial pressure of oxygen; after $2 \mathrm{~h}$ of reperfusion, the right pulmonary artery was clamped in the high-flow group $\left(^{*}\right)$. g Assessment of pulmonary arterial pressure; all data are depicted as median $\pm I Q R$ analyzed with repeated measures two-way ANOVA $(\mathrm{G})$ and post hoc multiple comparison test Sidak ( $\mathrm{x}$ ). Time is 6-h reperfusion; mPAP, mean pulmonary arterial pressure; after $2 \mathrm{~h}$ of reperfusion, the right pulmonary artery was clamped in the high-flow group $\left(^{*}\right)$

The impact of PA flow and physiological changes in the graft after reperfusion and in the early postoperative period is still debated $[18,19]$. However, compared to systemic organs, cessation of blood flow results in hypoxia, except in the lungs where adequate tissue oxygenation can be maintained through ventilation only [20]. The terms "mechanotransduction, mechanosensing, mechanosignaling" are referring to a signaling cascade sensed by the pulmonary endothelium when blood flow ceases [21]. Endothelial mechanotransduction by abrupt cessation of blood flow to understand the role of ischemiamediated ROS in signaling has been studied by other groups [21-26]. Al-Mehdi and 

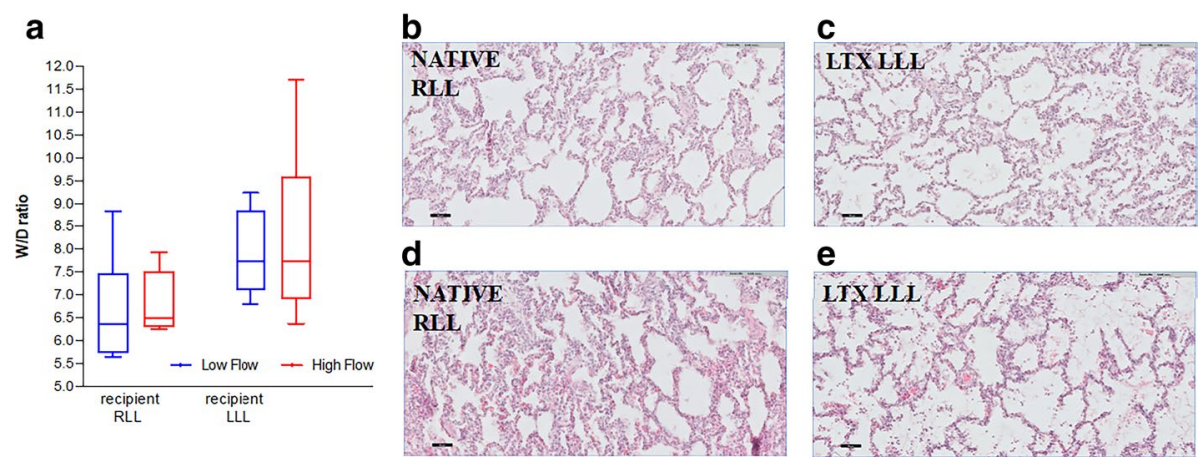

Fig. 3 Histology. a The W/D ratios were assessed of lung biopsies at the end after $6 \mathrm{~h}$ reperfusion. No significant difference was observed between the low- vs. high-flow group in the right native lug $(p=0.49)$ and the left transplanted lung $(p<0.99)$. Data were analyzed with Mann-Whitney test; W/D, wet-to-dry weight ratio; RLL, right lower lobe; LLL, left lower lobe. Left (b) The native right lower lobe (RLL) of the low-flow (LF) group shows mild capillary congestion and mild septal neutrophilic infiltration without presence of intra-alveolar neutrophils. Right (c) The transplanted left lower lobe (LLL) of the low-flow (LF) group shows mild capillary congestion, presence of septal neutrophilic infiltration, intra-alveolar edema and intra-alveolar neutrophils. Left (d) The native right lower lobe (RLL) of the high-flow (HF) group shows prominent capillary congestion and presence of neutrophilic infiltration in the septa. Right (e) The transplanted left lower lobe (LLL) of the (HF) group shows presence of capillary congestion, prominent intra-alveolar edema and presence of septal and intra-alveolar neutrophilic infiltration

Table 2 Cytokine measurements in plasma of low- vs high-flow group

\begin{tabular}{llccr}
\hline Cytokines & LLOQ $\mathbf{~ p g / m l ) ~}$ & LF & HF & $p$-value \\
\hline IFN-alpha & 0.6 & $0.5(0.3-3.6)$ & $0.9(0.6-1.4)$ & 0.33 \\
IFN-gamma & 4.5 & $5.4(4.6-12.9)$ & $13.9(10.4-46.9)$ & 0.10 \\
IL-1 beta & 3.2 & $11.3(5-299.1)$ & $17.4(8.3-32.9)$ & 0.59 \\
IL-10 & 18 & $56(24.7-535.5)$ & $73.5(55.2-89.2)$ & 0.70 \\
IL-12p40 & 30 & $510.1(221.6-720.3)$ & $265.5(214.6-901.6)$ & 0.82 \\
IL-4 & 1.5 & $2.5(0.7-5.4)$ & $1.9(1.8-2.5)$ & $>0.99$ \\
IL-6 & 5.9 & $73.5(36.9-745)$ & $150.4(102.1-260.2)$ & 0.18 \\
IL-8 & 16 & $43.1(22.1-1172)$ & $30.4(23.2-35.4)$ & 0.67 \\
TNF-alpha & 6.5 & $101.7(3.2-1139)$ & $3.2(3.2-85.7)$ & 0.32 \\
\hline
\end{tabular}

Cytokine measurements for the cytokines: interferon- $\alpha$ (IFN- $\alpha$ ), interferon- $\gamma$ (IFN- $\gamma$ ), interleukin-1 $\beta$ (IL-1 $\beta)$, interleukin-10 (IL-10), interleukin-12p40 (IL-12p40), interleukin-4 (IL-4), interleukin-6 (IL-6), interleukin-8 (IL-8) and tumor necrosis factor-a (TNF-a) were not significant in the low vs. high-flow group. Data are expressed as median ( $25 \%-75 \%$ interquartile range); and Mann-Whitney test was used for comparing the two groups; LLOQ lower limit of quantification, pg/ml, picogram/ milliliter, LF low flow, HF high flow

colleagues demonstrated in a rat model that a low perfusate flow rate can prevent activation of the loss of shear stress signaling cascade (mechanotransduction) [27].

Overall, in our model, ischemia-reperfusion injury measured by physiological, histological and immunological variables did not significantly differ between the HF and LF group [4, 28]. This might be explained due to the limited amount of graft injury in the donor lung. Despite a long cold ischemic interval, donor animals had no additional injury related to typical events in clinical donors such as brain death or aggressive management. Also, reperfusion time of the transplanted graft was limited to $6 \mathrm{~h}$ only.

General inflammatory markers such as IFN- $\alpha$, IFN- $\gamma$, IL-1 $\beta$, IL-10, IL-12p40, IL-4, IL-6, IL-8, TNF- $\alpha$ measured in the plasma at the beginning and in the end of the 


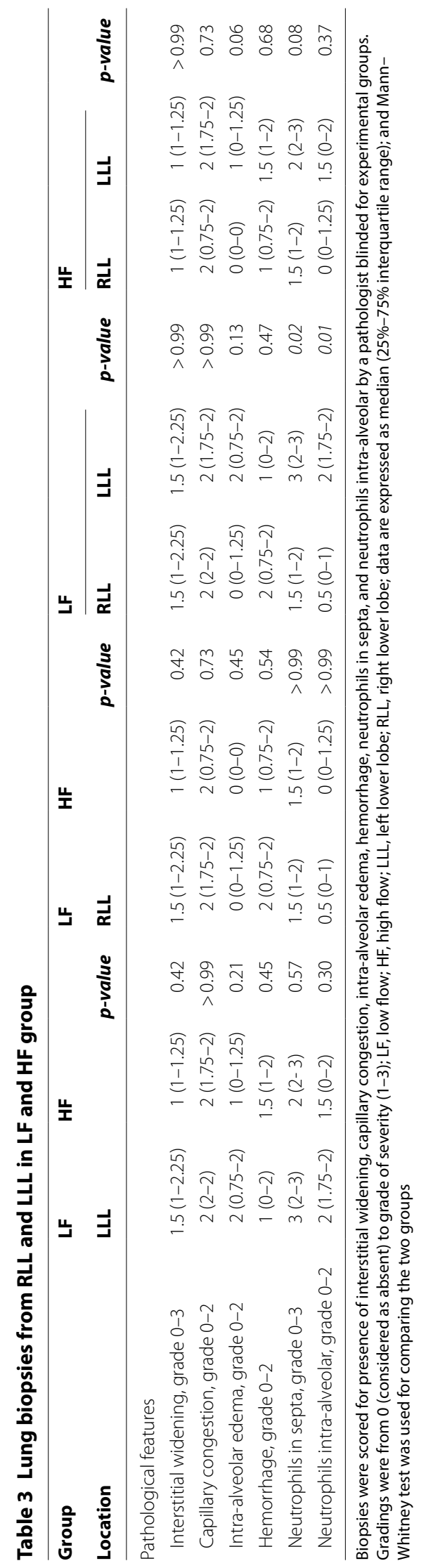


experiment, were increased in both groups, showing activation of the innate immune system, without differences between study groups. In this study, measurements of immunologic markers, reflecting lung injury, were measured at a very early time point. Hamilton et al. describe biomarkers associated with PGD within the first $72 \mathrm{~h}$ post-LTx. There is a clear peak of biomarkers reflecting lung injury between 8 and $24 \mathrm{~h}$ after LTx [29] Therefore, it is questionable how much lung injury can already be observed after 6-h reperfusion like in our porcine LTx model. Interestingly, not only the transplanted left lung showed histological injury, also the right native lung was damaged as reflected in the LF group as mild capillary congestion and mild septal neutrophilic infiltration without presence of intra-alveolar neutrophils. In the HF group, histological injury of the right native lung showed shows prominent capillary congestion and presence of neutrophilic infiltration in the septa.

The remaining question regarding this observation is whether injury of the right native lung was caused by ventilation, reperfusion injury, spillover of toxic agents from the left lung, or due to systemic stress response to the transplantation procedure. Probably all these mechanisms together apply. This should be further investigated.

A direct clinical implication of our model might be the question if extracorporeal technology should be installed during the transplant process to deviate a fraction of the flow away of the newly transplanted lung. Our data suggest implementing a right-toleft bypass circuit might be an important strategy during double-lung transplantation to protect the first allograft from high pulmonary flow and early onset of ischemia-reperfusion injury. In clinical practice, extracorporeal support with cardiopulmonary bypass or veno-arterial ECMO is already often used during lung implantation. Our data suggest that the reduction of the flow to the first implanted lung might be an important mechanism to explain the protective nature of ECMO in the development of PGD. Of course, clinical decision-making is often based on PA pressures and gas exchange, where high PAPs and low P/F ratios are guiding the initiation of ECMO. Finally, in the clinical setting veno-arterial ECMO might also be considered to avoid right ventricular failure in addition to supporting pulmonary function.

Practices regarding the use of these ECMO devices vary among transplant centers and no randomized data are available [30-33]. A left-single lung transplantation survival model with clamping of the right pulmonary artery was chosen because sequential bilateral lung transplantation in pigs is not possible because of anatomic differences with the presence of a separate tracheal bronchus to the right upper lobe and an accessory right lower lobe draining into the left inferior pulmonary vein. Our model allows the study of this concept in the future.

\section{Limitations}

Our study serves as a preclinical model to study ischemia-reperfusion injury. A potential limitation of our study is that we developed a porcine single-left lung transplantation model. This is because bilateral LTx in pigs is extremely difficult due to its anatomical variables compared to humans. Another limitation of our study is the fact that the left chest was left open after transplantation. This was necessary for technical reasons and control of clamping the right PA. Therefore, the ventilation data (compliance) are not reliable and do not reflect the compliance of the whole respiratory system. Also, we did 
not add a double-lumen tube and lung separation was not possible because of anatomical reasons (additional right upper lobe branching directly from the trachea). This adds to the fact that ventilation data could not separate left or right lung. Given these limitations, we have not reported on ventilatory parameters.

In addition, complete right hilar clamping is not feasible in a left lung transplanted pig for a 6-h survival model because of the high incidence of acute right heart failure. We realize that the absolute number of animals in each group is relatively low, especially to perform reliable statistical comparison. Nevertheless, we present a reproducible model with low variability in both groups. The primary goal of our study was to indicate the shortcomings of existing models and to open new perspectives to study ischemia-reperfusion injury in the future.

\title{
Conclusions
}

Porcine single-lung transplantation models remain demanding, but the setting is feasible.

In this model, we could demonstrate the feasibility of selectively studying the impact of pulmonary flow to the transplanted lung. In the studied large animal model, differential blood flow did not impact the development of pulmonary IRI at $6 \mathrm{~h}$ of reperfusion.

However, our findings might have an impact on future studies about intra-operative problems during bilateral sequential single-lung transplantation with extracorporeal life support.

\begin{abstract}
Abbreviations
ABP: Arterial blood pressure; BAL: Broncho-alveolar lavage; CO: Cardiac output; ELISA: Enzyme-linked immuno-sandwich assays; ECLS: Extracoporeal life support; $\mathrm{ETCO}_{2}$ : End-tidal carbon dioxide levels; HF: High flow; IFN-a: Interferon- $\mathrm{a}$; IFN- $\gamma$ : Interferon-ү; IL-1 $\beta$ : Interleukin-1 beta; IL-4: Interleukin-4; IL-6: Interleukin-6; IL-8: Interleukin-8; IL-10: Interleukin-10; IL12p40: Interleukin-12p40; IVC: Inferior vena cava; IRI: Ischemia-reperfusion injury; L: Liters; LA: Left atrium; LAP: Left atrial pressure; LF: Low flow; LLL: Left lower lobe; LLOQ: Lower limits of quantification; LPV: Left pulmonary vein; LTx: Lung transplantation; $\mathrm{P} / \mathrm{F}$ ratio: $\mathrm{P}_{2} \mathrm{O}_{2} / \mathrm{F}_{i} \mathrm{O}_{2}$ ratio; $\mathrm{PA}$ : Pulmonary artery; PAP: Pulmonary artery pressure; PEEP: Positive end-expiratory pressure; PGD: Primary graft dysfunction; PH: Pulmonary hypertension; PVR: Pulmonary vascular resistance; RLL: Right lower lobe; RPV: Right pulmonary vein; RR: Respiratory rate; RV: Right ventricular; SVC: Superior vena cava; TNF-a: Tumor necrosis factor-a; TV: Tidal volume; W/D: Wet-to-dry ratio.
\end{abstract}

Acknowledgements

The authors thank Mrs. Nicole Jannis for her valuable help and input during all experiments and the medical students Caroline Lauwers, Tom Lauwers, Cedric Vanluyten and Jozefien Van Ranst for their technical assistance during the experiments.

Also, Prof. Dr. Paul De Leyn is greatly thanked for his support during the study.

\section{Authors' contributions}

AEF, MO, BS, JK, TH and SO performed the research work and data collection. AEF and SEV performed the statistical analysis. AV scored all histology samples. SC, DS, AEF and SEV performed and interpreted the multiplex analysis. SEV, GMV, RV, APN, BMV, and DEVR contributed to the conception and design of the study and did the final revision of the article. All authors read and approved the final manuscript.

\section{Funding}

AN is supported by the KU Leuven (C24/18/073). AV is sponsored by a fundamental research Grant from the FWO (1102020 N). BMV is funded by the KU Leuven University (C24/15/030 and C16/19/005). SEV is sponsored by a grant from the Research Fund-Flanders (FWO 12G8715N). RV is a senior clinical research fellow of the FWO-Flanders. OCS solution was kindly offered by Transmedics (Andover, MA, USA) without any influence on our study. This research did not receive any other specific grants from funding agencies in the public, commercial, or not-for-profit sectors.

\section{Availability of data and materials}

The authors confirm that the data supporting the findings of this study are available within the article.

\section{Ethics approval and consent to participate}

This experimental porcine study (topig20 pigs, Zoötechnisch centrum KU Leuven, Lovenjoel, Belgium) was approved by the Ethics Committee on Animal Research KU Leuven (P011/2018). All animals received humane care in accordance with "Principles of Laboratory Animal care", formulated by the National Society for Medical Research and "Guide for the Care 
and Use of Laboratory Animals", prepared by the Institute of Laboratory Animal Resources and published by the National Institutes of Health, USA (NIH Publication No. 86-23, revised 1996).

\section{Consent for publication}

All authors have read and approved the final manuscript.

\section{Competing interests}

There are no competing interests.

\section{Author details}

${ }^{1}$ Department of Cardiovascular Sciences, KU Leuven, Leuven, Belgium. ${ }^{2}$ BREATHE, Department of Chronic Diseases, Metabolism and Ageing (Chrometa), Leuven Lung Transplant Unit, KU Leuven, Leuven, Belgium. ${ }^{3}$ Laboratory of Virology and Chemotherapy, Department of Microbiology and Immunology, Rega Institute for Medical Research, KU Leuven, Leuven, Belgium. ${ }^{4}$ Lung Transplant Unit, Hospital Universitari Vall D'Hebron, Barcelona, Spain. ${ }^{5}$ Department of Respiratory Diseases, University Hospitals Leuven, Leuven, Belgium. ${ }^{6}$ Department of Thoracic Surgery, University Hospitals Leuven, Leuven, Belgium. ${ }^{7}$ Department of Anesthesiology, University Hospitals Leuven, Leuven, Belgium.

Received: 21 August 2020 Accepted: 20 January 2021

Published online: 05 February 2021

\section{References}

1. Snell GI, Yusen RD, Weill D, Strueber M, Garrity E, Reed A et al (2017) Report of the ISHLT Working Group on Primary Lung Graft Dysfunction, part I: Definition and grading-A 2016 Consensus Group statement of the International Society for Heart and Lung Transplantation. J Heart Lung Transplant 36:1097-1103

2. Chemla D, Castelain V, Hervé P, Lecarpentier Y, Brimioulle S (2002) Haemodynamic evaluation of pulmonary hypertension. Eur Respir J 20:1314-1331

3. Diamond JM, Lee JC, Kawut SM, Shah RJ, Localio AR, Bellamy SL et al (2013) Clinical risk factors for primary graft dysfunction after lung transplantation. Am J Respir Crit Care Med 187:527-534

4. den Hengst WA, Gielis JF, Lin JY, Van Schil PE, De Windt LJ, Moens AL (2010) Lung ischemia-reperfusion injury: a molecular and clinical view on a complex pathophysiological process. Am J Physiol Heart Circ Physiol 299:H1283-H1299

5. de Perrot M, Liu M, Waddell TK, Keshavjee S (2003) Ischemia-reperfusion-induced lung injury. Am J Respir Crit Care Med 167:490-511

6. Chatterjee S (2018) Endothelial mechanotransduction, redox signaling and the regulation of vascular inflammatory pathways. Front Physiol 9:524

7. Chiu JJ, Wung BS, Shyy JY, Hsieh HJ, Wang DL (1997) Reactive oxygen species are involved in shear stress-induced intercellular adhesion molecule-1 expression in endothelial cells. Arterioscler Thromb Vasc Biol 17:3570-3577

8. Matute-Bello G, Frevert CW, Martin TR (2008) Animal models of acute lung injury. Am J Physiol Lung Cell Mol Physiol 295:L379-L399

9. Karimi A, Cobb JA, Staples ED, Baz MA, Beaver TM (2011) Technical pearls for swine lung transplantation. J Surg Res 171:e107-e111

10. Mariscal A, Caldarone L, Tikkanen J, Nakajima D, Chen M, Yeung J et al (2018) Pig lung transplant survival model. Nat Protoc 13:1814-1828

11. Van De Wauwer C, Neyrinck A, Geudens N, Rega F, Verleden GM, LerutT et al (2006) Modification of the arterial anastomotic technique improves survival in porcine single lung transplant model. Acta Chir Belg 106:450-457

12. Matthews JC, McLaughlin V (2008) Acute right ventricular failure in the setting of acute pulmonary embolism or chronic pulmonary hypertension: a detailed review of the pathophysiology, diagnosis, and management. Curr Cardiol Rev 4:49-59

13. Karapanos NT, Wettstein PJ, Li Z, Huebner M, Park SJ, Deschamps C et al (2012) Does lung ischemia and reperfusion have an impact on coronary flow? A quantitative coronary blood-flow analysis with inflammatory cytokine profile. Eur J Cardiothorac Surg 41:154-161

14. Moreno I, Vicente R, Ramos F, Vicente JL, Barberá M (2007) Determination of interleukin-6 in lung transplantation: association with primary graft dysfunction. Transplant Proc 39:2425-2426

15. Pearce ML, Yamashita J, Beazell J (1965) Measurement of pulmonary EDEMA. Circ Res 16:482-488

16. Lang G, Aigner C, Winkler G, Shkirdladze K, Wisser W, Dekan G et al (2009) Prolonged venoarterial extracorporeal membrane oxygenation after transplantation restores functional integrity of severely injured lung allografts and prevents the development of pulmonary graft failure in a pig model. J Thorac Cardiovasc Surg 137:1493-1498

17. Hoeper MM, Benza RL, Corris P, de Perrot M, Fadel E, Keogh AM et al (2019) Intensive care, right ventricular support and lung transplantation in patients with pulmonary hypertension. Eur Respir J 53:1

18. Singh RR, Laubach VE, Ellman PI, Reece TB, Unger E, Kron IL et al (2006) Attenuation of lung reperfusion injury by modified ventilation and reperfusion techniques. J Heart Lung Transplant 25:1467-1473

19. Fiser SM, Kron IL, Long SM, Kaza AK, Kern JA, Cassada DC et al (2002) Controlled perfusion decreases reperfusion injury after high-flow reperfusion. J Heart Lung Transplant 21:687-691

20. Al-Mehdi AB, Shuman H, Fisher AB (1997) Oxidant generation with K(+)-induced depolarization in the isolated perfused lung. Free Radic Biol Med 23:47-56

21. Chatterjee S, Nieman GF, Christie JD, Fisher AB (2014) Shear stress-related mechanosignaling with lung ischemia: lessons from basic research can inform lung transplantation. Am J Physiol Lung Cell Mol Physiol 307:L668-L680 
22. Browning E, Wang H, Hong N, Yu K, Buerk DG, DeBolt K et al (2014) Mechanotransduction drives post ischemic revascularization through K(ATP) channel closure and production of reactive oxygen species. Antioxid Redox Signal 20:872-886

23. Chatterjee S, Chapman KE, Fisher AB (2008) Lung ischemia: a model for endothelial mechanotransduction. Cell Biochem Biophys 52:125-138

24. Davies PF (2009) Hemodynamic shear stress and the endothelium in cardiovascular pathophysiology. Nat Clin Pract Cardiovasc Med 6:16-26

25. Chatterjee S, Fisher AB (2014) Mechanotransduction: forces, sensors, and redox signaling. Antioxid Redox Signal 20:868-871

26. Tarbell JM, Simon SI, Curry FR (2014) Mechanosensing at the vascular interface. Annu Rev Biomed Eng 16:505-532

27. Al-Mehdi AB, Zhao G, Fisher AB (1998) ATP-independent membrane depolarization with ischemia in the oxygenventilated isolated rat lung. Am J Respir Cell Mol Biol 18:653-661

28. Weyker PD, Webb CA, Kiamanesh D, Flynn BC (2013) Lung ischemia reperfusion injury: a bench-to-bedside review. Semin Cardiothorac Vasc Anesth 17:28-43

29. Hamilton BC, Kukreja J, Ware LB, Matthay MA (2017) Protein biomarkers associated with primary graft dysfunction following lung transplantation. Am J Physiol Lung Cell Mol Physiol 312:L531-L541

30. Hoetzenecker K, Donahoe L, Yeung JC, Azad S, Fan E, Ferguson ND et al (2018) Extracorporeal life support as a bridge to lung transplantation-experience of a high-volume transplant center. J Thorac Cardiovasc Surg 155(1316-28):e1

31. Hoetzenecker K, Schwarz S, Muckenhuber M, Benazzo A, Frommlet F, Schweiger T et al (2018) Intraoperative extracorporeal membrane oxygenation and the possibility of postoperative prolongation improve survival in bilateral lung transplantation. J Thorac Cardiovasc Surg 155(2193-206):e3

32. Hashimoto K, Hoetzenecker K, Yeung JC, Jeagal L, Donahoe L, Pierre A et al (2018) Intraoperative extracorporeal support during lung transplantation in patients bridged with venovenous extracorporeal membrane oxygenation. J Heart Lung Transplant 37:1418-1424

33. Benazzo A, Schwarz S, Frommlet F, Schweiger T, Jaksch P, Schellongowski P et al (2019) Twenty-year experience with extracorporeal life support as bridge to lung transplantation. J Thorac Cardiovasc Surg 157(2515-25):e10

\section{Publisher's Note}

Springer Nature remains neutral with regard to jurisdictional claims in published maps and institutional affiliations.

\section{Submit your manuscript to a SpringerOpen ${ }^{\circ}$ journal and benefit from:}

- Convenient online submission

- Rigorous peer review

- Open access: articles freely available online

- High visibility within the field

- Retaining the copyright to your article

Submit your next manuscript at $\gg$ springeropen.com 